\title{
Educação como situação gnosiológica e via para pensar complexo
}

João Henrique Suanno*

Universidade Estadual de Goiás suanno@uol.com.br

\author{
Marilza Vanessa Rosa Suanno** \\ Universidade Federal de Goiás - UFG \\ marilzasuanno@uol.com.br
}

Márcia de Fátima Ferreira Balieiro***

Secretaria Municipal de Educação marcia.ff.b@hotmail.com

\section{Resumo}

Esse artigo apresenta reflexões em torno da obra 'Extensão ou comunicação?', de Paulo Freire (2013), que foi inspiração para a elaboração de projetos desenvolvidos na Escola Municipal João Paulo I, no município de Goiânia/Goiás, em parceria com o Estágio Curricular Obrigatório do curso

* Pós-doutor em Educação - UB/Espanha, 2014. Doutor em Educação UCB/DF, 2013. Mestre em Educação - UH/Cuba, 2003. Psicólogo - PUC/ GO, 1991. Professor efetivo do Programa de Pós-Graduação Interdisciplinar em Educação, Linguagem e Tecnologias - PPG-IELT/UEG. suanno@uol. com.br

** Pós-doutora em Educação - UFT/TO, 2021. Doutora em Educação - UCB/ DF, 2015. Mestre em Educação - UH/Cuba, 2003. Pedagoga - UFG/GO, XXXX. Professora efetiva do Programa de Pós-Graduação em Educação da Faculdade de Educação, da Universidade Federal de Goiás - PPGE-FE/ UFG.marilzasuanno@uol.com.br

*** Graduada em Pedagogia pela Pontifícia Universidade Católica de Goiás (2002). Especialista em Métodos e Técnicas de Ensino pela Universidade Salgado de Oliveira (2004). Docente efetiva da Rede Municipal de Educação de Goiânia/Goiás (2003-). Atuou na Coordenação Pedagógica da Educação de Adolescentes Jovens e Adultos - EAJA da Escola Municipal João Paulo I (2005-2018). Atualmente Professora regente da Educação Infantil da Escola Municipal Olegário Moreira Borges.marcia.ff.b@hotmail.com 
de Pedagogia da Faculdade de Educação da Universidade Federal de Goiás - UFG. O estudo da obra de Paulo Freire nos mobilizou a pensar o ato pedagógico como um ato gnosiológico com potencialidade para auxiliar o ser humano em seu processo de humanização, bem como impulsionar o esforço coletivo de construção de uma sociedade democrática que contribua para o enfrentamento das desigualdades e injustiças. Para tal, recorre-se ao sentido gnosiológico do termo extensão, para além dos equívocos de estender ações e da alienação da ignorância. A reflexão valoriza e respeita o lugar simbólico de pertença de cada pessoa no mundo sem que se imponha a compreensão de quem chega, em uma relação que se inicie como seres humanos em processo de autorreconhecimento, de produção coletiva e de transformação. Os projetos educativos desenvolvidos na Educação de Adolescentes, Jovens e Adultos - EAJA e apresentados nessa publicação tiveram a intenção de pensar complexo (MORIN, 2011) sobre metatemas, ou seja, temas fundamentais para rever os caminhos da humanidade.

Palavras-chave: Educação. Escola. Estágio.

\section{Education as a gnosiological situation and route to thinking complex}

\section{Abstract}

This article presents reflections on the work 'Extension or communication?', by Paulo Freire (2013), which was an inspiration for the development of projects developed at the João Paulo I Municipal School, in the city of Goiânia/Goiás, in partnership with the Internship Mandatory Curriculum for the Pedagogy course at the Faculty of Education of the Federal University of Goiás - UFG. The study of Paulo Freire's work mobilized us to think of the pedagogical act as a gnosiological act with the potential to help human beings in their humanization process, as well as boost the collective effort to build a democratic society that contributes to the confrontation of inequalities and injustices. To do so, we resort to the gnosiological meaning of the term extension, beyond the mistakes of extending actions and the alienation of ignorance. Reflection values and respects the symbolic place of belonging of each person in the world without imposing the understanding of those who arrive, in a relationship that begins as human beings in a process of self-recognition, collective production and transformation. The educational projects developed in Education for Adolescents, Youth and Adults - EAJA and presented in this publication were intended to think complex (MORIN, 2011) about metathemes, that is, fundamental themes to review the paths of humanity. Keywords: Education. School. Internship. 


\section{La educación como situación gnosiológica y ruta al complejo de pensamiento}

\section{Resumen}

Este artículo presenta reflexiones sobre el trabajo 'Extensión o comunicación?', De Paulo Freire (2013), que sirvió de inspiración para el desarrollo de proyectos desarrollados en la Escuela Municipal João Paulo I, en la ciudad de Goiânia / Goiás, en alianza el Currículo Obligatorio de Pasantías para el curso de Pedagogía en la Facultad de Educación de la Universidad Federal de Goiás - UFG. El estudio de la obra de Paulo Freire nos movilizó a pensar en el acto pedagógico como un acto gnosiológico con potencial para ayudar al ser humano en su proceso de humanización, así como impulsar el esfuerzo colectivo por construir una sociedad democrática que contribuya al enfrentamiento de las desigualdades y injusticias. Para ello, recurrimos al significado gnosiológico del término extensión, más allá de los errores de acciones prolongadas y la alienación de la ignorancia. La reflexión valora y respeta el lugar simbólico de pertenencia de cada persona en el mundo sin imponer el entendimiento de quienes llegan, en una relación que comienza como seres humanos en un proceso de autorreconocimiento, producción colectiva y transformación. Los proyectos educativos desarrollados en Educación para Adolescentes, Jóvenes y Adultos - EAJA y presentados en esta publicación tenían como objetivo pensar de manera compleja (MORIN, 2011) sobre metatemas, es decir, temas fundamentales para revisar los caminos de la humanidad.

Palabras clave: Educación. Escuela. Prácticas.

\section{Introdução}

"Ensinar exige respeito aos saberes dos educandos"

(Paulo Freire)

O que caracteriza uma educação libertadora? Uma educação como situação gnosiológica? Perguntas como essas nos motivaram a escrever esse artigo inspirados na obra intitulada Extensão ou Comunicaşão? (FREIRE, 2013) e no desejo de compartilhar experiências escolares desenvolvidas nos últimos anos e que se desafiaram a pensar complexo (MORIN, 2011) sobre metatemas. 
As reflexões de Paulo Freire têm nutrido o trabalho docente e o agir pedagógico na Educação de Adolescentes, Jovens e Adultos - EAJA nas últimas décadas e, nesse artigo, apresentamos algumas articulações de tal fundamentação-inspiração com dois projetos desenvolvidos na Escola Municipal João Paulo I, em parceria com o estágio curricular obrigatório do curso de Pedagogia da Faculdade de Educação da Universidade Federal de Goiás. Tais projetos foram orientados em diálogo com a coordenação pedagógica da EAJA e com a equipe de supervisores(as) de estágio da referida Escola. No quadro 1, apresentamos dados dos projetos e os respectivos anos.

Quadro 1. Projetos desenvolvidos

\begin{tabular}{|c|c|c|c|c|}
\hline Projeto & Escola & $\begin{array}{c}\text { Coordenação } \\
\text { Pedagógica } \\
\text { da EAJA }\end{array}$ & $\begin{array}{c}\text { Orientadora } \\
\text { do Estágio } \\
\text { (Pedagogia } \\
\text { FE/UFG) }\end{array}$ & Ano \\
\hline $\begin{array}{l}\text { Projeto Transdis- } \\
\text { ciplinar Economia } \\
\text { Solidária }\end{array}$ & $\begin{array}{c}\text { Escola } \\
\text { Municipal } \\
\text { João Paulo } \\
\text { I (Goiânia/ } \\
\text { GO) }\end{array}$ & $\begin{array}{l}\text { Profa. Márcia } \\
\text { de Fátima Fer- } \\
\text { reira Balieiro }\end{array}$ & $\begin{array}{c}\text { Profa. Marilza } \\
\text { Vanessa Rosa } \\
\text { Suanno }\end{array}$ & 2014 \\
\hline $\begin{array}{l}\text { Projeto de Tra- } \\
\text { balho Transdis- } \\
\text { ciplinar Hortas } \\
\text { Urbanas e Hortas } \\
\text { Escolares }\end{array}$ & $\begin{array}{c}\text { Escola } \\
\text { Municipal } \\
\text { João Paulo } \\
\text { I (Goiânia/ } \\
\text { GO) }\end{array}$ & $\begin{array}{l}\text { Profa. Márcia } \\
\text { de Fátima Fer- } \\
\text { reira Balieiro. }\end{array}$ & $\begin{array}{c}\text { Profa. Marilza } \\
\text { Vanessa Rosa } \\
\text { Suanno }\end{array}$ & 2016 \\
\hline
\end{tabular}

Fonte: Suanno, Suanno e Balieiro (2021)

Os dois projetos partem da compreensão de que a história de cada ser humano é marcada pela cultura, pela sociedade, pelo momento histórico no qual se encontra inserido e pelas oportunidades acessadas ao longo da vida. Partindo desta perspectiva, compreende-se que ao trilhar seus caminhos cada um imprime sua marca no mundo, troca com outros seus sentidos construídos que 
se transformam nas relações estabelecidas, podendo ampliar ainda mais seus sentidos subjetivos e sua leitura do mundo.

Assim, os sentidos e os significados construídos dependem das relações estabelecidas ao longo dos caminhos trilhados, das pegadas deixadas e que se sobrepõem e convivem no mesmo chão, porém com temporalidades e espaços únicos de percepções e aprendizagens. $\mathrm{O}$ que nos remete à ideia de existências conectadas entre si, ou seja, somos quem somos porque somos todos nós - conforme a filosofia sul-africana Ubuntu.

Nesse sentido, a escola constitui-se como espaço coletivo que pode possibilitar a formação humana, a construção de conhecimentos e as interconexões entre saberes, sentidos e modos de agir consciente, o que é importante no processo de humanização do ser e de transformação do mundo. De tal modo, almeja-se que as situações e atividades escolares sejam coletivas, participativas e dialógicas superando os limites já denunciados por Freire (2013, p. 28) quando reflete que "conhecer, [...] não é o ato através do qual um sujeito, transformado em objeto, recebe, dócil e passivamente, os conteúdos que outro lhe dá ou impõe”.

Para conhecer é preciso exercitar o ato de pensar, problematizar, relacionar e, assim, indagar o mundo. Para tal, a escola precisa construir ambientes de estudo e práxis-inventivas que sejam dialógicas, pois:

O conhecimento, pelo contrário, exige uma presença curiosa do sujeito em face do mundo. Requer sua ação transformadora sobre a realidade. Demanda uma busca constante. Implica invenção e reinvenção. Reclama a reflexão crítica de cada um sobre o ato mesmo de conhecer, pelo qual se reconhece conhecendo e, ao reconhecer-se assim, percebe o 'como' de seu conhecer e os condicionamentos a que está submetido seu ato. Conhecer é tarefa de sujeitos, não de objetos. E é como sujeito e somente enquanto sujeito, que o homem pode realmente conhecer (FREIRE, 2013, p. 28-29).

Almeja-se que no ato de conhecer o sujeito aproprie-se do aprendido e assuma uma postura em frente ao mundo. 
Por isso mesmo é que, no processo de aprendizagem, só aprende verdadeiramente aquele que se apropria do aprendido, transformando-o em apreendido, com o que pode, por isso mesmo, reinventá-lo; aquele que é capaz de aplicar o aprendido-apreendido a situações existenciais concretas (FREIRE, 2013, p. 29).

Reinventar o mundo é um desafio que deve nutrir os projetos escolares e a formação humana. Portanto, contextos educativos devem estimular a curiosidade epistemológica, a autonomia de pensamento, a liberdade de expressão e a construção de conhecimentos para que o sujeito construa o seu lugar no mundo. Nos dois projetos desenvolvidos no estágio, buscamos enfrentar o reinventar as situações educativas, as relações com o conhecimento e o estilo de pensamento (MORIN, 2011).

A educação tomada como prática da liberdade nos mobiliza a entender que cada pessoa tem seu lugar como parte da transformação do mundo. Portanto, os ambientes de aprendizagem deveriam favorecer o compartilhamento de curiosidades, conhecimentos e interpretações de mundo. "É necessário que, na situação educativa, educador e educando assumam o papel de sujeitos cognoscentes, mediatizados pelo objeto cognoscível que buscam conhecer" (FREIRE, 2013, p. 29).

Pensar a educação como prática da liberdade a partir do estudo da obra Extensão ou comunicação? (FREIRE, 2013) remete à reflexão de que para o autor, o termo extensão expressa uma invasão cultural, que não se baseia no diálogo e na "autêntica educação" (FREIRE, 2013, p. 07). Para ele, a acepção do termo extensão está vinculada ao paradigma tradicional, que coisifica o ser humano, o que impede a transformação da vida e, consequentemente, do mundo.

Parece-nos fecunda a reflexão de Freire (2013) sobre o termo extensão ao propor que superemos ser esta a ideia de quem planeja ações que se estendessem daquilo que é seu para partilhar com os outros, uma vez que, para o autor, uma ação extensionista necessariamente precisa ser pensada e planejada em interação com o meio e com os sujeitos envolvidos nas ações, deflagrando 
assim, a busca de soluções de enfrentamento das interveniências humanas e naturais que necessitam de reflexões e, consequentes ações transformadoras, sendo este um caminho para uma educação extensionista libertadora. Ou seja, a construção coletiva de um movimento de humanização com a criação de sentidos e significados que, em outras circunstâncias, mesmo sem a presença daquele que promoveu a ação de extensão, poderão continuar refletindo sobre o mundo em que estão inseridos e as maneiras de transformá-lo.

De tal modo, propõe-se um ciclo gnosiológico, ou seja, a relação entre o conhecimento já estruturado cognitivamente, o processo de ensino e o processo de aprendizagem do conhecimento a que se pretende que seja ainda construído. Nesses processos, a relação entre aquele que está para realizar uma ação extensionista e as pessoas que estão para a interação com ele, nesse ciclo, são levadas em consideração tanto no processo de autorreflexão quanto na aprendizagem compartilhada. A título de exemplo, vale ilustrar que em um dos dois projetos relatados na sequência envolvemos a participação na escola de membros de cooperativas de economia solidária. Assim, a relação estabelecida com os cooperados, uma comunidade externa à universidade e externa à escola, demandou das organizadoras profundas reflexões sobre como encaminhar as atividades, as relações, os lugares de fala e o protagonismo de todos no referido projeto.

Economia Solidária é uma temática que nos remete a reflexões profundas sobre sociedade, economia e relações de produção e de trabalho. O desafio de pensar tal temática a partir da Epistemologia da Complexidade nos remete a rever o humanismo planetário, a governança global e processos econômicos que segundo Morin (2011) deveriam ser capazes de promover simultaneamente processos de globalização e desglobalização; crescimento e decrescimento; desenvolvimento e involução; transformação e conservação. E assim, rever a relação entre ser humano, natureza e sociedade por meio da reforma do pensamento que se articula com a reforma do pensamento político, o que impulsionaria a elaboração de política de humanidade, de política de civilização, assim como poderia con- 
tribuir para estimular a reforma da educação, e, enfim, da reforma do estilo de vida.

Morin (2011) por meio da proposição da relação contraditória entre globalização e desglobalização estimula a última dando assim visibilidade a economia local e regional. A título de exemplo, o fortalecimento da economia local por meio do abastecimento do comércio dos bairros com produções de pequenos agricultores impulsionaria qualidade de vida e redução da emissão de poluentes. Referimo-nos à ações simples como o abastecimento do comércio dos bairros com verduras e legumes oriundos de hortas familiares com cultivo orgânico. Tal ação impulsionaria a revitalização das cidades e dos bairros o que poderia resultar em um processo de mudança e de humanização, não só da economia, mas, e porque não, da relação entre as pessoas que ali residem impulsionando a melhoria da qualidade de vida com mais dignidade e cidadania.

Temáticas como a exposta podem ser impulsionadoras do ciclo gnosiológico, que em Freire (2013), é um processo formativo-educativo que pode ser nutrido por projetos que versem como por exemplo sobre economia solidária e são gerativos de processos de conscientização sobre a valorização das pessoas, dos recursos locais, dos cultivos de proximidade e do entorno.

Paulo Freire propõe a superação do sentido irruptivo da educação, ou seja, a superação do "equívoco gnosiológico" (FREIRE, 2013, p. 08) no qual se planeja e desenvolve ações sem levar em consideração os atores, os ambientes, suas realidades e as interações que advêm deles. Um equívoco gnosiológico está no sentido da extensão como entendimento de algo de quem leva para aquele que recebe, como expectadores da ação de outrem. Nos dois projetos desenvolvidos no estágio, relatados na sequência, ninguém era expectador, todos eram levados em consideração e tinha vez, voz e ação.

A partir do referencial gnosiológico, a ação da extensão está em desvelar e revelar para aquele que interage com o mundo, os conteúdos estendidos. Essa é uma preocupação que devemos nos ater a fim de que possamos atuar em sociedade, como docentes e 
aprendizes que todos somos, de maneira a valorizar e respeitar o lugar simbólico de pertença que cada pessoa ocupa no mundo e, daí, interagir respeitando seu olhar, suas necessidades, seus interesses, seus objetivos, sem que se imponha a compreensão de quem chega.

Movidos pelo verbo esperançar, pelo ato de animar-se à busca de algo, criamos os projetos que relatamos na sequência.

\section{Projeto Transdisciplinar Economia Solidária}

"A leitura de mundo precede a da palavra".

(Paulo Freire)

No ano de 2014, inspirados nas reflexões de Freire (2013), Suanno (2013), Gadotti (2009) e Hernandez (1998) criamos e desenvolvemos o Projeto Transdisciplinar Economia Solidária movidos pelo desejo de pensar complexo e transdisciplinar sobre o tema gerador. O projeto foi desenvolvido nos anos iniciais do ensino fundamental, na modalidade Educação de Adolescentes, Jovens e Adultos - EAJA. Para nós, pensar complexo é um estilo de pensamento que demanda o esforço de religar saberes, conhecimentos, práticas e culturas em torno de uma temática. A dinâmica transdisciplinar impulsiona e mobiliza olhares multidimensionais, multirreferenciais e autorreferenciais. O que, em âmbito escolar, favorece a coexistência entre disciplinaridade e transdisciplinaridade.

A escolha da temática desencadeou uma rica problematização com os estudantes da EAJA. A economia solidária foi compreendida como experiência popular de autogestão e cooperação econômica que se propõe à construção de rupturas nas relações de produção de viés capitalista. Para Gaiger $(2014$, p. 18) "representariam a emergência de um novo modo de organização do trabalho e das atividades econômicas". Para Singer (2005, p. 19, grifo nosso):

a economia solidária é um ato pedagógico em si mesmo, na medida em que propõe uma nova prática social e um entendimento novo dessa prática. A única maneira de aprender a construir a economia solidária é praticando-a. Mas seus valores fundamentais precedem sua prática. 
Laville (1994, p. 211) destaca que a "economia solidária organiza-se a partir de fatores humanos, favorecendo as relações em que o laço social é valorizado através da reciprocidade e adota formas comunitárias de propriedade".

Ao dialogarmos sobre o tema, os adolescentes, jovens, adultos e idosos se mobilizaram com relatos de experiência, curiosidades, questões e opiniões de toda ordem, o que desencadeou o estudo coletivo. Ao longo do período em que o projeto foi desenvolvido, a frequência e a participação nas aulas foram surpreendentes, de tal modo, estagiárias, supervisores(as) de estágio, orientadora de estágio e coordenação pedagógica da escola tiveram que mover-se na busca de textos e documentários, assim como contactando cooperativas, associações, movimentos organizados para que pudessem estar conosco na Escola e compartilhar experiências, tirar dúvidas, orientar interessados em criar cooperativas, dentre outros. A respeito do Projeto Transdisciplinar Economia Solidária, a coordenadora da escola relatou:

\begin{abstract}
Nós, da equipe da Escola Municipal João Paulo I (direção, coordenação e professores e alunos) ao receber a Professora Marilza Suanno, e as estagiárias da UFG já sabíamos que naquele ano de 2014 surgiria um dos projetos mais significativos e que mudaria a vivência de muitos alunos através do tema Economia Solidária e Sustentabilidade trabalhado com os alunos do I Segmento da EAJA ( $1^{\mathrm{a}}$ à $4^{\mathrm{a}}$ série). Podemos relatar que foi um projeto encantador, um dos mais incríveis que já participei, vindo para contemplar o PPP (Projeto Político Pedagógico) da Escola Municipal João Paulo I e, também, a Proposta Político Pedagógica da EAJA da Rede Municipal da Educação (RME) de Goiânia. Proposta esta que é pautada nas concepções de Paulo Freire e em ações que partem dos conhecimentos prévios e da realidade dos alunos, considerando suas prioridades, necessidades e conhecimentos de mundo. Buscamos construir uma educação inovadora e emancipatória (FREIRE, 1992).
\end{abstract}

O projeto só foi possível dada a parceria entre universidade (estágio), escola e cooperativas solidárias. Adotou-se uma metodologia dialógica e transdisciplinar na construção da compreensão do 
conceito de economia solidária e na produção de articulações com autogestão, cooperação, cooperativas solidárias, gestão participativa, comércio justo, consumo sustentável, ajuda mútua, emancipação, respeito ao meio ambiente, valorização da diversidade, valorização do saber local, democracia, dentre outros. A coordenadora da escola registrou que:

\begin{abstract}
Os educandos e os professores ficaram animados com as palestras, as rodas de conversa e se engajaram na proposta do projeto de estágio sobre economia solidária. Cada um com seus interesses, curiosidades, conhecimentos e habilidades contribuíram com o estudo e as ações planejadas para o desenvolvimento do projeto. O planejamento que era flexível e ia incorporando as sugestões dos participantes. Debatemos sobre associações, cooperativas e pequenos negócios que complementariam rendas familiares, dentre outros temas pertinentes sobre economia solidária e sustentabilidade. Nesses momentos, propiciando aos alunos, professores, estagiários e convidados vOz ativa e efetiva interatividade com as ideias do projeto, encorajando-o ao domínio dos objetivos da proposta. Amadurecidas as ideias e os conhecimentos, chegou o grande dia, organizamos uma feira de economia solidária na escola, uma atividade sem fins lucrativos e aberta à comunidade.
\end{abstract}

Na referida Feira, várias cooperativas compareceram, expuseram e venderam seus produtos para a comunidade escolar, membros da universidade e pessoas do entorno da Escola João Paulo I que estiveram presentes. Os estudantes da EAJA também tiveram espaço na feira para realizarem e expor suas produções, pois vários eram artesãos, quitandeiras, crocheteiras, bordadeiras, cozinheiras, marceneiros, pintores, dentre outros. Comentou a coordenadora da Escola:

Este dia, apesar de ser considerado o encerramento do projeto, foi, em verdade, o início de uma nova etapa para os alunos envolvidos, uma vez que, ao tornar público os seus interesses, habilidades e campo de atuação puderam ter reconhecimento do coletivo, estabelecer trocas, aproximações e, também, a possibilidade de obter ganhos. Ganharam muito em conhecimento, autoconfiança e percepção sobre a existência de novos caminhos para o respectivo desenvolvimento pessoal e profissional. Alguns estudantes desempregados se aproximaram de cooperativas buscando 
uma outra via possível. Durante a realização desse projeto houve muito envolvimento, interação e diálogo entre os estudantes da EAJA, professores da escola, estagiários, professora da universidade e convidados de cooperativas solidárias. Foi muito significativo. Considero que "Ensinar não é transferir conhecimentos, mas criar possibilidades para a sua própria produção ou a sua construção" (FREIRE, 1996).

Arroyo (2006, p. 53) considera que a economia popular e solidária tem entre seus principais fundamentos o desafio de estruturar "uma economia que se alimente da inclusão social e da distribuição de renda, em um contexto em que signifique a radicalização da democracia política na direção da democracia econômica, a única capaz de trazer soluções definitivas aos problemas sociais". Para Morin (2011, p. 55), economia solidária pode fortalecer o sentimento de pertencimento, solidariedade e liberdade. Ou seja,

ao mesmo tempo, seria promovida uma "economia solidária" que prolongaria, sob novas formas, a economia mútua: iniciativas baseadas na solidariedade local ou, pelo contrário, que despertar essa solidariedade; formação de cooperativas e associações sem fins lucrativos que prestarão serviços sociais locais. Uma sociedade não pode progredir em complexidade, isto é, em liberdade, autonomia e comunidade ao mesmo tempo, se não progride em solidariedade: de fato, a complexidade crescente comporta liberdades crescente, com maiores possibilidades de iniciativa, que tanto podem resultar em processos fecundos, como podem ser destrutivas e geradoras de desordem. A desordem extrema torna-se principalmente destrutiva e a extrema complexidade degenera então em desintegração do todo em elementos soltos. A única forma de salvaguardar a complexidade de uma sociedade, ou seja, suas liberdades, com um mínimo de autoridade repressiva, não pode ser outra que o intenso sentimento de pertencimento à comunidade.

Aumentar as liberdades e as iniciativas transformadoras, conforme Morin (2011) é um desafio e uma possibilidade fecunda. Ordem, desordem e reorganização podem emergir no processo, nesse caso, na economia solidária, que se autogestiona em um movimento dinâmico de autonomia e de dependência. 
Solidariedade, cooperação e autogestão são a base da economia solidária, uma perspectiva comunitária insurgente que fortalece o sentimento de autonomia e de liberdade. A autogestão é um desafio e um processo formativo guiado por princípios compartilhadas.

Gadotti (2009) considera que economia solidária é um conceito ligado à educação transformadora e à democracia econômica, pois por meio do trabalho cooperativo-comunitário tomam-se decisões coletivas, prezam-se pelo respeito ao meio ambiente, pela produção sem utilização da mão de obra infantil, pelo respeito à cultura local, pela cidadania e pela igualdade. O que implica, também, em comércio justo, cooperação, segurança no trabalho comunitário, equilíbrio de gênero e consumo sustentável (produzido sem o sofrimento de pessoas ou de animais), sendo a margem de lucro discutida coletivamente entre o produtor e o vendedor. Sendo, que estes processos envolvem princípios, propostas e pessoas comprometidas com um mundo mais solidário, ético e sustentável.

\section{Projeto Hortas Urbanas e Hortas Escolares}

O Projeto Hortas Urbanas e Hortas Escolares foi desenvolvido ao longo do estágio curricular obrigatório do curso de Pedagogia FE/UFG, realizado no ano de 2016, na Escola João Paulo I, e buscou, por um lado, resgatar o Projeto Horta Escolar que tinha sido desenvolvido por vários anos na referida Escola e tinha contado com a colaboração, partipação e manutenção realidazada pela comunidade escolar, assim como por moradores vizinhos da escola. Por outro lado, colocou os estudantes da EAJA em diálogo com um tema emergente e desconhecido pela maioria, ou seja, as hortas urbanas e os movimentos organizados em torno delas. O referido projeto vinculou-se ao Projeto Político Pedagógico da Escola e ao projeto EAJA “Trabalho, Cidadania, Meio Ambiente e Diversidade Cultural" que se encontrava em andamento naquele ano letivo.

O objetivo do projeto foi pensar complexo e transdisciplinar religando saberes e práticas em torno do metatema hortas urbanas e hortas escolares. Para tal, lemos com os estudantes da EAJA di- 
versas reportagens jornalísticas, assistimos a documentários e dialogamos sobre temas diversos e relacionados, quais sejam: a) hortas urbanas; b) hortas escolares; c) hortas hidropônicas; d) hortas orgânicas); e) relação ser humano, natureza e sociedade; f) tipos de cultivo (monocultura, agronegócio, agricultura sintrópica, agroflorestal, agroecologia, agricultura familiar); g) relação agricultura e sustentabilidade; h) relação entre produção de alimentos, saúde e alimentação saudável); i) compostagem; j) alimentos transgênicos e orgânicos; k) cultivo e uso de agrotóxicos, l) dentre outros.

Elaborar um projeto educativo para pensar complexo sobre práticas socias e realidades nos remete a compreensão do complexo, "significa que devemos considerar os dados particulares em relação ao todo do qual fazem parte, e também considerar o todo em relação às partes" (MORIN, 2011, p. 79). De tal modo, pensar complexo para impulsionar a reforma de vida no século XXI nos remete a diversos desafios dentre eles impulsionar um novo desenvolvimento de economia de proximidade (na agricultura, na horticultura, no artesanato e nas pequenas e médias empresas), bem como o desenvolvimento da economia verde, enquanto processo de reorganização e reconversão econômica cujo crescimento compensaria eficazmente o decrescimento do consumo de energia e da emissão de dióxido de carbono e de gases poluente responsáveis pelo efeito estufa. Morin (2011) estimula o desenvolvimento de todas as fontes de energia renováveis (eólica, maré motriz, geotérmica, solar) e destaca que tal perspectiva impulsionaria grandes obras que gerariam emprego em todos os continentes.

Em concordância com o exposto, nos estudos e diálogos desse projeto sobre hortas urbanas e hortas escolares, podemos compreender a horta escolar para além da produção de alimentos para a complementação da merenda escolar tendo essa sido valorizada como ambiente de aprendizagem, de convivência e de aprimoramento dos conhecimentos e das prática de cultivo de hortaliças e vegetais. De acordo com as estagiárias Sousa, Viana e Silva (2016, p. 1) que participaram deste projeto: 
Hortas, inseridas no ambiente escolar, podem ser um laboratório vivo que possibilita o desenvolvimento de diversas atividades pedagógicas coletivas, cooperativas, transdisciplinares e transformadoras. O presente projeto promoveu diálogos, aprendizagens e relações humanas significativas em torno da reflexão sobre a atual relação ser humano/natureza/sociedade/cultura.

As hortas urbanas foram compreendidas como espaços que estimulam o fortalecimento do vínculo entre as pessoas e o fortalecimento do vínculo com o cultivo de alimentos, oportunizando vivências outras em espaço urbano.

Ao longo do projeto nos surpreendemos com estudantes relatando que passaram a cultivar hortas em suas casas e apartamentos, assim como começaram a observar os setores de Goiânia para idenfiticar onde era possível reconhecer hortas urbanas. $O$ projeto contou com aulas teóricas, práticas, trocas de experiência e rodas de conversa. Assim como diversas atividades, tais como: oficina de plantio de mudas de hortaliças em garrafa pet; confecção de composteira doméstica; criação na escola de um jardim biodiverso com plantio de ervas medicinais; revitalização da horta da escola e cultivo de plantas ornamentais na entrada da escola. Assim como, sistematizamos os estudos e as oficinas em mapas conceituais e mandala de saberes que foram base para as produções textuais que se seguiram. A coordenadora da escola registrou que:

O Projeto Hortas Urbanas e Escolares alcançou dimensões maiores dentro da Secretaria Municipal de Educação de Goiânia e na Gerência Regional de Educação de Jovens e Adultos por estar em consonância com a Proposta Político Pedagógica da EAJA da RME de Goiânia e embasada nas concepções freireanas de educação. Esse projeto movimentou alunos, professores e funcionários. Os resultados desse projeto foram apresentados pela coordenação pedagogia da Escola em dois eventos importantes da EAJA na SME.

Em paralelo ao Projeto Hortas Urbanas e Hortas Escolares que era desenvolvido nos dias de estágio curricular obrigatório do curso de Pedagogia FE/UFG com a presença da orientadora e das 
estagiárias, a coordenadora pedagógica relatou que os professores e as professoras da Escola construíram várias atividades de estudo vinculadas ao tema do referido projeto. Veja:

O professor de Ciências organizou palestras sobre o tema, exibiu vídeos e promoveu plantio de mudas (ervas aromáticas e hortaliças) no jardim biodiverso recém-criado na Escola em parceria com o estágio do curso de Pedagogia FE/UFG. A professora de Arte reaproveitou materiais para confecção de pequenos canteiros e vasos, já a professora de História contextualizou e fez reflexões históricas sobre o surgimento e desenvolvimento da agricultura. A professora de Português trabalhou a leitura e interpretação de textos sobre a qualidade de vida e alimentação saudável. A professora de Inglês incluiu no vocabulário em estudo um conjunto de palavras do projeto como por exemplo: horta, cultivo, verduras, legumes e hortaliças. $\mathrm{O}$ professor de Matemática trabalhou cálculos e medidas de canteiros e custos de produção de hortaliças. A professora de Geografia trabalhou o espaço urbano para a produção de alimentos em hortas urbanas. A professora de Educação Física relacionou alimentação, saúde e movimento.

A Escola promovia todo final de ano uma "Mostra Pedagógica" e no dia 26/11/2016 tivemos a oportunidade de expor os resultados do Projeto Hortas Urbanas e Hortas Escolares para toda a comunidade escolar, envolvendo os estudantes dos três turnos e suas famílias.

\section{Considerações finais}

A presente publicação apresentou caminhos trilhados na busca por impulsionar uma Educação de Adolescente, Jovens e Adultos de viés libertador, compreendendo a situação educativa como gnosiológica (FREIRE, 2013), por auxiliar o ser humano em seu processo de humanização, viabilizando processos e projetos de trabalho que valorizaram e respeitaram o lugar simbólico de pertença de cada pessoa, o diálogo como estratégia e assumindo o desafio de pensar complexo (MORIN, 2011) religando saberes, conhecimentos e práticas em torno de metatemas (SUANNO et al, 2018) selecionados pela equipe. Esse foi um esforço coletivo construídos 
e compartilhado entre a professora orientadora de estágio do curso de Pedagogia FE/UFG, a coordenadora pedagógica da escola-campo de estágio, os professores e as professoras que realizavam a supervisão do estágio, os estagiários e os estudantes da EAJA. Momentos de reflexão, diálogos e partilha na relação dos sujeitos com o conhecimento, com a vida e com o compromisso por um outro mundo, mais democrático, justo, fraterno e ecológico.

\section{Referências}

ARROYO, Miguel González. Educação de Jovens - adultos: um campo de direitos e responsabilidade pública. In: SOARES, Leôncio Soares (Org.). Diálogos na educação de jovens e adultos. Belo Horizonte: Autentica, 2006, $2^{\circ}$ edição.

FREIRE, Paulo. Extensão ou comunicação? Rio de Janeiro: Paz e Terra, 2013.

FREIRE, Paulo. Pedagogia da Autonomia: saberes necessários à prática educativa. São Paulo: Paz e Terra, 1996.

FREIRE, Paulo. Pedagogia da Esperança: um reencontro com a Pedagogia do Oprimido. Rio de Janeiro: Paz e Terra, 1992.

GADOT'TI, Moacir. Educação Integral no Brasil: inovações em processo. São Paulo: Editora e Livraria Instituto Paulo Freire, 2009.

GAIGER, L. et al. A economia solidária no Brasil: uma análise de dados nacionais. São Leopoldo: Oikos, 2014.

HERNÁNDEZ, F. Transgressão e mudança na educação: os projetos de trabalho. Tradução de Jussara Haubert Rodrigues. Porto Alegre: Artmed, 1998.

LAVILLE, J.-L. L'économie solidaire: une perspective internationale. Paris, Desclée de Brouwer, col. "Sociologie économique", 1994.

MORIN, Edgar. La Vía. Para el futuro de la humanidade. Tradução Núria Petit Fontseré. Barcelona: Paidós, 2011.

SINGER, Paul. A economia solidária como ato pedagógico. In: Kruppa, Sonia M. Portella (org.). Economia solidária e educação de jovens e de adultos. Brasília: Inep/MEC, p. 15-20, 2005. 
SOUZA, Elisangela Ferreira de; VIANA, Elistane Pereira; SILVA, Maria Cleumar da; SUANNO, Marilza Vanessa Rosa. Projeto de Trabalho Transdisciplinar Hortas Urbanas e Hortas Escolares. VI Seminário de Estágio do Curso de Pedagogia (FE/UFG): os desafios da prática docente: interlocuções com o estágio. 2016. Disponível em: https://files.cercomp.ufg.br/weby/up/235/o/PROJETO_ DE_TRABALHO_TRANSDISCIPLINAR_HORTAS_URBANAS_E_HORTAS_ESCOLARES.pdf. Acesso em 04/05/2021.

SUANNO, João Henrique. Escola Criativa e Práticas Pedagógicas Transdiciplinares e Ecoformadoras. Tese de Doutorado. Defesa em 09 de maio de 2013. Orientação da Profa. Dra. Maria Cândida Moraes. Brasília/DF: Universidade Católica de Brasília -UCB, 2013.

SUANNO, Marilza Vanessa Rosa; LOPES, Flavio Marques; DEUS JÚNIOR; Getúlio Antero de; DEWULF, Nathalie de Lourdes Souza; BOLLELA, Valdes. Metodologias Ativas, Transdisciplinaridade e Aprendizagens na Universidade Federal de Goiás (UFG). Revista Desafios UFT. Revista Desafios - v. 5, n. 02, 2018. Disponível em: https://core.ac.uk/download/pdf/267891677.pdf Acesso em: 02/05/2021. 